\title{
Synergistic Induction of Chicken Antimicrobial Host Defense Peptide Gene Expression by Butyrate and Sugars
}

OPEN ACCESS

Edited by:

Wang Jiajun,

Northeast Agricultural University,

China

Reviewed by:

Chanisa Kiatsurayanon,

Ministry of Public Health, Thailand

Corwin D. Nelson,

University of Florida, United States

Xiangbing Mao,

Sichuan Agricultural University, China

*Correspondence:

Guolong Zhang

zguolon@okstate.edu

tThese authors have contributed equally to this work

Specialty section:

This article was submitted to Antimicrobials, Resistance and

Chemotherapy,

a section of the journal

Frontiers in Microbiology

Received: 23 September 2021 Accepted: 12 November 2021 Published: 09 December 2021

Citation:

Yang $Q$, Fong $L-A$, Lyu $W$, Sunkara $L T$, Xiao K and Zhang G (2021)

Synergistic Induction of Chicken Antimicrobial Host Defense Peptide

Gene Expression by Butyrate and

Sugars.

Front. Microbiol. 12:781649.

doi: 10.3389/fmicb.2021.781649

\author{
Qing Yang ${ }^{1 \dagger}$, Li-An Fong ${ }^{1 \dagger}$, Wentao Lyu ${ }^{1,2}$, Lakshmi T. Sunkara ${ }^{1,3}$, Kan Xiao ${ }^{1,4}$ and \\ Guolong Zhang ${ }^{\text {1* }}$
}

${ }^{1}$ Department of Animal and Food Sciences, Oklahoma State University, Stillwater, OK, United States, ${ }^{2}$ State Key Laboratory for Managing Biotic and Chemical Threats to the Quality and Safety of Agro-Products, Institute of Agro-Product Safety and Nutrition, Zhejiang Academy of Agricultural Sciences, Hangzhou, China, ${ }^{3}$ Veterinary Diagnostic Center, Clemson University, Clemson, SC, United States, ${ }^{4}$ Hubei Key Laboratory of Animal Nutrition and Feed Science, Hubei Collaborative Innovation Center for Animal Nutrition and Feed Safety, Wuhan Polytechnic University, Wuhan, China

Antimicrobial resistance is a major concern to public health demanding effective alternative strategies to disease control and prevention. Modulation of endogenous host defense peptide (HDP) synthesis has emerged as a promising antibiotic alternative approach. This study investigated a potential synergy between sugars and butyrate in inducing HDP gene expression in chickens. Our results revealed that sugars differentially regulated HDP expression in both gene- and sugar-specific manners in chicken HD11 macrophage cells. Among eight mono- and disaccharides tested, all were potent inducers of avian $\beta$-defensin 9 (AvBD9) gene $(p<0.05)$, but only galactose, trehalose, and lactose obviously upregulated cathelicidin-B1 (CATHB1) gene expression. The expression of AvBD14 gene, on the other hand, was minimally influenced by sugars. Moreover, all sugars exhibited a strong synergy with butyrate in enhancing $A v B D 9$ expression, while only galactose, trehalose, and lactose were synergistic with butyrate in CATHB1 induction. No synergy in AvBD14 induction was observed between sugars and butyrate. Although lactose augmented the expression of nearly all HDP genes, its synergy with butyrate was only seen with several, but not all, HDP genes. Mucin-2 gene was also synergistically induced by a combination of lactose and butyrate. Furthermore, lactose synergized with butyrate to induce AvBD9 expression in chicken jejunal explants $(p<0.05)$. Mechanistically, hyper-acetylation of histones was observed in response to both butyrate and lactose, relative to individual compounds. Mitogen-activated protein kinase, NF-кB, and cyclic adenosine monophosphate signaling pathways were also found to be involved in butyrate- and lactose-mediated synergy in AvBD9 induction. Collectively, a combination of butyrate and a sugar with both HDP-inducing and barrier protective activities holds the promise to be developed as an alternative to antibiotics for disease control and prevention.

Keywords: antimicrobial resistance, antibiotic alternatives, host defense peptides, antimicrobial peptides, sugar, monosaccharide, lactose, butyrate 


\section{INTRODUCTION}

Routine use of antibiotics at subtherapeutic levels in feed for animal growth promotion and disease prophylaxis has been linked to the emergence of antibiotic-resistant bacteria in humans (Manyi-Loh et al., 2018; Mcewen and Collignon, 2018). It is a global trend to phase out in-feed antibiotics, necessitating the development of alternatives to antibiotics to maintain the productivity and health of food-producing animals. Host defense peptides (HDPs), also known as antimicrobial peptides, constitute an essential component of the innate immunity system (Robinson et al., 2015; Hancock et al., 2016; Ting et al., 2020). Dietary modulation of endogenous HDP synthesis has the potential to be developed as a novel antibiotic-free approach to disease control with a minimum risk of triggering antimicrobial resistance (Lyu et al., 2015; Robinson et al., 2018; Bergman et al., 2020; Rodriguez-Carlos et al., 2021).

In vertebrate animals, defensins and cathelicidins represent two major families of HDPs (Zhang and Sunkara, 2014; Rodriguez-Carlos et al., 2021). A total of $14 \beta$-defensins known as AvBD1-14 and four cathelicidins (CATH1-3 and CATHB1) have been reported in chickens (Zhang and Sunkara, 2014). HDPs are produced in myeloid and/or epithelial cells lining the digestive, respiratory, and urogenital tracts (Zhang and Sunkara, 2014; Hancock et al., 2016). HDPs exert direct antimicrobial activities against Gram-negative and Gram-positive bacteria, fungi, and enveloped viruses with a minimum of risk triggering resistance. HDPs also play a range of immunomodulatory roles such as chemotaxis, activation of immune cells, and modulation of inflammation and autophagy (Hancock et al., 2016; Robinson et al., 2018). Additionally, HDPs contribute to maintaining epithelial homeostasis by inducing mucins and tight junction proteins (Robinson et al., 2015). Down-regulation of HDPs is employed by certain pathogens to evade host defense and establish infections, while stimulation of endogenous HDP synthesis has shown potential for antimicrobial therapy (Hancock et al., 2016; Robinson et al., 2018; Bergman et al., 2020; Rodriguez-Carlos et al., 2021). Several classes of compounds such as histone deacetylase inhibitors (HDACi), short-chain fatty acids, and vitamin $\mathrm{D}_{3}$ have been shown to promote HDP synthesis without triggering inflammation (Lyu et al., 2015; Bergman et al., 2020; RodriguezCarlos et al., 2021).

Butyrate is a major species of short-chain fatty acids produced by bacterial fermentation of undigested dietary fibers (Liu et al., 2018). Butyrate induces HDPs in humans, chickens, cattle, and pigs (Robinson et al., 2018; Rodriguez-Carlos et al., 2021) and confers protection against infections (Sunkara et al., 2011; Xiong et al., 2016). Butyrate induces HDPs by acting mainly as an HDACi to increase acetylation of core histones and relaxation of the target gene promoter (Kida et al., 2006; Robinson et al., 2018), and mitogen-activated protein kinase (MAPK) signaling pathways are also involved (Schauber et al., 2003). Sugars are represented by a group of dietary carbohydrates containing 1-2 monomeric sugar units and include monosaccharides, disaccharides, and sugar alcohols (Cummings and Stephen, 2007). Glucose has been found to enhance human $\beta$-defensin
1 (DEFB1) gene expression in keratinocytes (Cruz Diaz et al., 2015) and renal cells (Malik and Al-Kafaji, 2007), but decrease DEFB3 and DEFB4 in keratinocytes (Lan et al., 2011, 2012) and human cathelicidin antimicrobial peptide (CAMP) gene in monocyte-derived macrophages (Montoya-Rosales et al., 2016). However, lactose, a disaccharide derived from condensation of galactose and glucose, is capable of inducing the CAMP gene in human intestinal epithelial cells that involves MAPK, but not cyclic adenosine 3,5-monophosphate (cAMP) signaling (Cederlund et al., 2013). The induction of CAMP expression is also observed with several other mono- and disaccharides in the same study (Cederlund et al., 2013). Moreover, lactose is synergistic with butyrate in CAMP induction (Cederlund et al., 2013). The impact of lactose and its potential synergy with butyrate in HDP synthesis in other animal species and particularly non-mammalian species such as poultry remains unknown. Species-specific induction of HDPs in fact exists. For example, vitamin $\mathrm{D}_{3}$ is a potent inducer for human CAMP gene (Wang et al., 2004), but has a minimum ability to induce HDP expression in chickens (Zhang et al., 2016) and loses its activity completely in mice (Gombart et al., 2005).

To evaluate whether lactose can activate HDP gene expression and whether the synergy exists between lactose and butyrate in chickens, we studied the expression of three representative chicken HDP genes including $A v B D 9, A v B D 14$, and CATHB1 in chicken HD11 macrophage cells in response to lactose and butyrate individually and in combination. We further extended our study to a panel of eight different mono- and disaccharides for their HDP-inducing ability and their synergy with butyrate in chicken cells. Additionally, the mechanisms by which butyrate and lactose induce $A v B D 9$ gene expression were examined.

\section{MATERIALS AND METHODS}

\section{Culture and Stimulation of Chicken HD11 Cells}

Chicken HD11 macrophage cells (Sunkara et al., 2011, 2014) were maintained in complete RPMI 1640 medium (HyClone, Logan, UT, United States) containing 10\% fetal bovine serum (Atlanta Biologicals, Flowery Branch, GA, United States), $100 \mathrm{U} / \mathrm{ml}$ penicillin, and $100 \mu \mathrm{g} / \mathrm{ml}$ streptomycin (Lonza, Walkersville, MD, United States). After overnight seeding at $2 \times 10^{6}$ cells/well in 6-well cell culture plates, cells were stimulated with $0.1 \mathrm{M}$ or $0.2 \mathrm{M}$ of various sugars in the presence or absence of $2 \mathrm{mM}$ sodium butyrate (all from MilliporeSigma, St. Louis, MO, United States) for 3, 6, 12, 24, or $48 \mathrm{~h}$, followed by RNA isolation and gene expression analysis as described below. To study the role of different signaling pathways in HDP induction, $50 \mu \mathrm{M}$ PD98059, $20 \mu \mathrm{M}$ SP600125, $25 \mu \mathrm{M}$ SB203580, $0.1 \mu \mathrm{M}$ QNZ, or $1 \mathrm{~mm}$ SQ22536 were incubated with cells $1 \mathrm{~h}$ prior to treatment with $2 \mathrm{mM}$ butyrate and/or $0.2 \mathrm{M}$ lactose for $24 \mathrm{~h}$. To further probe the involvement of the Ras-Raf-MEK-ERK-RSK pathway, HD11 cells were pretreated with specific inhibitors including BAY43 $(10,20$, and $40 \mu \mathrm{M}), \operatorname{U0126}(5,10,20$, and $40 \mu \mathrm{M}), \operatorname{PD} 98059(25,50,100$, and $200 \mu \mathrm{M}), \operatorname{AG} 126(25,50$, and $100 \mu \mathrm{M})$, or SL0101 $(10,20$, and $40 \mu \mathrm{M})$ for $1 \mathrm{~h}$ prior to 
stimulation with $2 \mathrm{mM}$ butyrate for $24 \mathrm{~h}$. All inhibitors were purchased from Santa Cruz Biotechnology (Dallas, TX, United States) or Cayman Chemical (Ann Arbor, Michigan, United States) and dissolved in dimethyl sulfoxide (DMSO).

\section{Preparation, Culture, and Stimulation of Chicken Jejunal Explants}

The jejunal segments were harvested from 1- to 2-week-old broiler chickens, washed, cut into a series of $0.5-\mathrm{cm}$-long segments, and then cultured individually in 6-well plates as we previously described (Sunkara et al., 2014; Lyu et al., 2018). Each segment was stimulated with $0.1 \mathrm{M}$ lactose with or without $2 \mathrm{mM}$ butyrate and incubated in a Hypoxia Chamber (StemCell Technologies, Vancouver, BC, Canada) filled with $95 \% \mathrm{O}_{2}$ and $5 \% \mathrm{CO}_{2}$ at $37^{\circ} \mathrm{C}$ for $24 \mathrm{~h}$. Jejunal segments were then centrifuged and homogenized in RNAzol RT for RNA extraction.

\section{Quantitative Reverse Transcription-PCR}

HD11 cells were lysed, and jejunal explants were homogenized in RNAzol RT (Molecular Research Center, Cincinnati, OH, United States) for extraction of total RNA. The first-strand cDNA was synthesized from 300 ng of total RNA using Maxima ${ }^{\circledR}$ First Strand cDNA Synthesis Kit (Thermo Fisher Scientific, Pittsburgh, PA, United States) in $4 \mu \mathrm{l}$. Real-time PCR was then performed using QuantiTech ${ }^{\circledR}$ SYBR Green I PCR kit (Qiagen, Valencia, CA, United States) and MyiQ Real-Time PCR Detection System (Bio-Rad, Hercules, CA, United States) in $10-\mu$ l reactions containing $1 / 10$ of the first-strand cDNA and gene-specific primers for $A v B D 1-10, A v B D 14, C A T H B 1$, mucin-2 (MUC2), or claudin 1 (CLDN1). PCR cycling conditions were $95^{\circ} \mathrm{C}$ for $10 \mathrm{~min}$, followed by 40 cycles of $94^{\circ} \mathrm{C}$ for $15 \mathrm{~s}, 55^{\circ} \mathrm{C}$ for $20 \mathrm{~s}$, and $72^{\circ} \mathrm{C}$ for $30 \mathrm{~s}$. The specificity of PCR reactions was confirmed by the melting curve analysis. The gene expression levels were quantified using the comparative $\Delta \Delta \mathrm{Ct}$ method with the glyceraldehyde-3-phosphate dehydrogenase $(G A P D H)$ gene as a reference for data normalization as described (Sunkara et al., 2011, 2014). Primers for chicken HDP genes and GAPDH used in the current study were as previously described (Sunkara et al., 2011). The primers for MUC2 were TCTGGAGAGAGTTGTCCTGAC (forward) and TCCTTGCAGCAGGAACAACT (reverse), while TTCCAACCAGGCTTTATGATG (forward) and TGCAGAGTCAGGTCAAACAGA (reverse) were used for CLDN1.

\section{Western Blot Analysis}

Chicken HD11 cells were stimulated with $0.2 \mathrm{M}$ lactose in the presence or absence of $2 \mathrm{mM}$ butyrate for 6,12 , or $24 \mathrm{~h}$, followed by wash with phosphate buffered saline and lysis in the radioimmunoprecipitation (RIPA) lysis buffer (Santa Cruz Biotechnology). Protein concentration was measured using the Bradford Assay (Bio-Rad). To determine the levels of histone $\mathrm{H} 4$ acetylation, $20 \mu \mathrm{g}$ proteins were separated in $12.5 \%$ SDS-PAGE gels and then transferred to polyvinylidene difluoride (PVDF) membranes. After overnight blocking in the blocking buffer containing 5\% dry skim milk in TTBS $(0.05 \%$ Tween $20,20 \mathrm{~mm}$ Tris- $\mathrm{HCl}, 150 \mathrm{~mm} \mathrm{NaCl}, \mathrm{pH} 7.5)$ at $4^{\circ} \mathrm{C}$, the membranes were incubated with a primary rabbit antibody against acetyl-histone
H4 (Cell Signaling, Danvers, MA, United States) or a rabbit antibody against $\beta$-actin (MilliporeSigma) in the blocking buffer for $1 \mathrm{~h}$ at room temperature. After three washes in TTBS, the membrane was incubated with an alkaline phosphataseconjugated goat anti-rabbit IgG antibody (MilliporeSigma) for $45 \mathrm{~min}$ at room temperature. Western blots were visualized with Western Blotting Luminol Reagent (Santa Cruz Biotechnology).

\section{Statistical Analysis}

Statistical analysis and data visualization were implemented in GraphPad Prism (GraphPad Software, La Jolla, CA, United States). The results were expressed as means \pm standard error of the mean (SEM) from 2 to 3 independent experiments. Statistics was performed with one-way ANOVA and post hoc Tukey's test. The results were considered statistically significant if $p<0.05$.

\section{RESULTS}

\section{Time- and Concentration-Dependent Induction of HDP Genes by Sugars}

To determine whether chicken HDP genes are induced by sugars, chicken HD11 macrophages were treated with three monosaccharides (glucose, galactose, and fructose), four disaccharides (lactose, maltose, sucrose, and trehalose), and a sugar alcohol (mannitol; Figure 1). All sugars at $0.2 \mathrm{M}$ clearly stimulated $A v B D 9$ gene expression in a time-dependent manner. $A v B D 9$ was readily induced as early as $3 \mathrm{~h}$, peaked at $6 \mathrm{~h}$, and then gradually declined to nearly basal levels at 24 and $48 \mathrm{~h}$ (Figure 2A). All five sugars including mannitol showed a comparable efficacy in $A v B D 9$ induction, each with a peak response of an approximately 50- to 100-fold increase. Apparently, sugar-mediated HDP induction was gene-specific. Although the kinetics of the CATHB1 mRNA expression was similar to that of $A v B D 9$ with a peak response at $6 \mathrm{~h}$, different sugars showed a dramatic variation in their potency to induce CATHB1. Galactose led to a greater than 200-fold maximum increase in CATHB1 expression at $6 \mathrm{~h}$, whereas lactose gave only approximately 20 -fold induction, with glucose, fructose, and mannitol showing a minimum two-fold to five-fold peak induction (Figure 2B). In the case of $A v B D 14$, a peak induction occurred as early as $3 \mathrm{~h}$ for lactose, glucose, and fructose, while galactose had a maximum induction at $6 \mathrm{~h}$ (Figure 2C). However, only a maximum of five-fold to eight-fold change was observed with lactose, galactose, glucose, and mannitol, with essentially no induction seen with fructose (Figure 2C).

Sugar-triggered AvBD9 induction was also in a strong dose-dependent manner. All sugars at $0.1 \mathrm{M}$ showed a marginal effect on $A v B D 9$ induction at $6 \mathrm{~h}$, while $0.2 \mathrm{M}$ gave a substantial induction in HD11 cells (Figure 3A). As for CATHB1, only galactose, trehalose, and lactose triggered an obvious dosedependent induction at $6 \mathrm{~h}$, with $0.2 \mathrm{M}$ galactose giving an approximately 150 -fold increase, $0.2 \mathrm{M}$ trehalose giving an approximately 40 -fold increase, and $0.2 \mathrm{M}$ lactose leading to a 20 -fold induction (Figure $3 \mathbf{B}$ ). Other sugars including 
Monosaccharides $\left(\mathrm{C}_{6} \mathrm{H}_{12} \mathrm{O}_{6}\right)$

Sugar alcohol $\left(\mathrm{C}_{6} \mathrm{H}_{14} \mathrm{O}_{6}\right)$

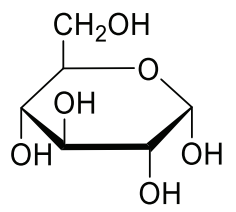

Glucose

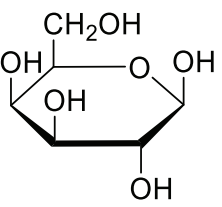

Galactose<smiles>OC[C@@H]1O[C@H](CO)[C@H]2O[C@H]1O2</smiles>

Fructose<smiles>OC[C@@H](O)[C@@H](O)[C@H](O)[C@H](O)CO</smiles>

Mannitol

\section{Disaccharides $\left(\mathrm{C}_{12} \mathrm{H}_{24} \mathrm{O}_{12}\right)$}

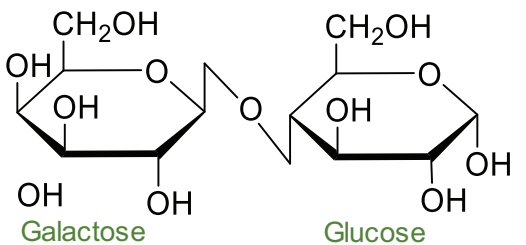

Lactose

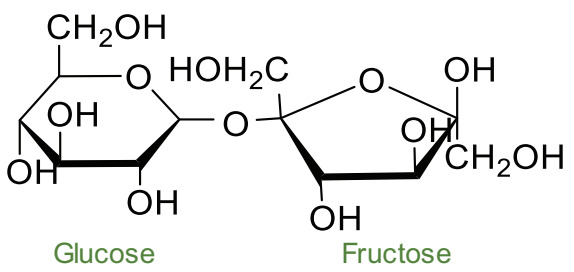<smiles>OCC1OC(OC2C(CO)OC(O)C(O)C2O)C(O)C2OC1O2</smiles>

Glucose

Maltose

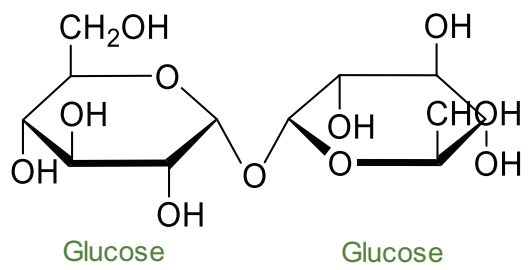

Trehalose

FIGURE 1 | Chemical structure of mono- and disaccharide sugars and sugar alcohol tested in this study. Haworth projections of the chemical structures were drawn using ChemDraw JS (https://chemdrawdirect.perkinelmer.cloud/js/sample/index.html).

maltose, glucose, sucrose, fructose, and mannitol had no or a negligible impact on CATHB1 induction. AvBD14 mRNA expression was minimally induced by most sugars, except for galactose causing an approximately five-fold increase at $0.2 \mathrm{M}$ (Figure 3C).

\section{Synergistic Induction of HDP and MUC2 Gene Expression by Butyrate and Lactose}

To further explore a potential synergy between sugars and butyrate in HDP induction, we treated chicken HD11 cells with $2 \mathrm{mM}$ butyrate and $0.2 \mathrm{M}$ lactose individually or in combination for various lengths of time. As expected, butyrate triggered a peak response with an approximately 1,750-fold $A v B D 9$ induction at $24 \mathrm{~h}$, whereas lactose gave a maximum 350 -fold $A v B D 9$ induction at $6 \mathrm{~h}$ (Figure 4A). Desirably, a combination of butyrate and lactose resulted in synergistic enhancement of $A v B D 9$ expression at nearly all time points except for $3 \mathrm{~h}$. A peak response was seen at $12 \mathrm{~h}$ with a nearly 70,000-fold increase, and the synergistic induction was sustained for at least $48 \mathrm{~h}$ (Figure 4A). Butyrate and lactose also synergistically improved $C A T H B 1$ transcription, peaking at $24 \mathrm{~h}$ with a 2,000-fold induction (Figure 4B). Although butyrate and lactose enhanced $A v B D 14$ expression individually albeit at much lower magnitudes, no obvious synergy was observed when they were used together (Figure 4C), reinforcing the notion of differential regulation of HDP genes by lactose and butyrate.

In addition, several other HDP genes such as $A v B D 3$, $A v B D 8$, and $A v B D 10$ were synergistically induced by a combination of butyrate and lactose (Figure 5A). For example, lactose alone strongly increased $A v B D 10$ expression and further synergized with butyrate to strengthen $A v B D 10$ transcription. A synergistic enhancement of $A v B D 3$ and $A v B D 8$ expressions was also observed at $12 \mathrm{~h}$ or $24 \mathrm{~h}$. However, the remaining HDP genes were moderately affected by lactose and butyrate with no obvious synergy observed (Figure 5A). It is important to note that most HDP genes were induced by butyrate with a peak induction at $24 \mathrm{~h}$, but lactose induced HDP genes rather quickly peaking at $6 \mathrm{~h}$ in many cases with a notable exception being $A v B D 10$, which exhibited a time-depending increase with a maximum induction at $24 \mathrm{~h}$ (Figure 5A). The strongest synergy occurred at 12 or $24 \mathrm{~h}$ for most HDP genes.

Because of our interest in mucosal immunity and barrier integrity, two major genes involved in barrier function, namely MUC2 and CLDN1, were also evaluated. Interestingly, lactose induced MUC2 quickly showing a maximum induction in 
A

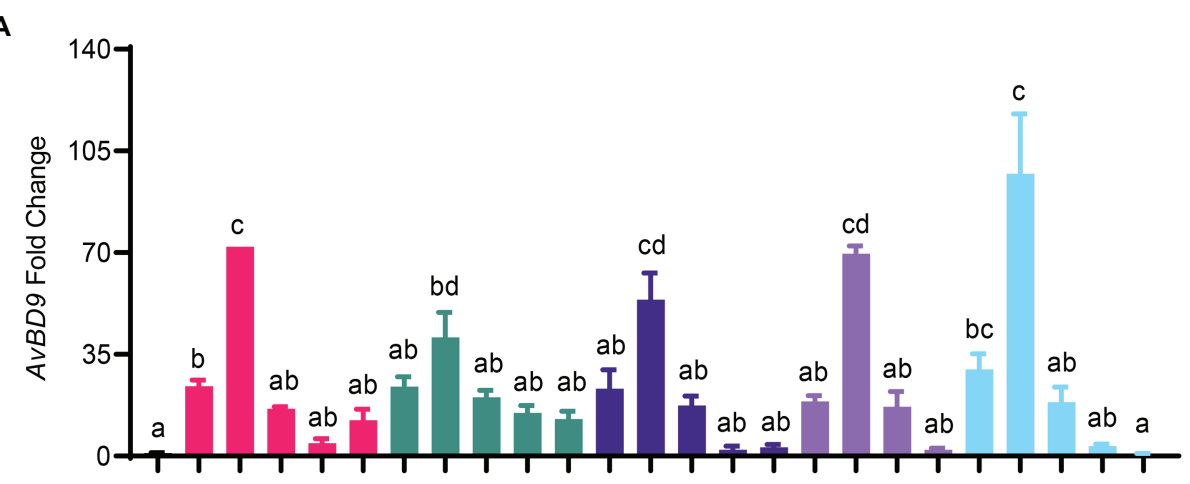

B

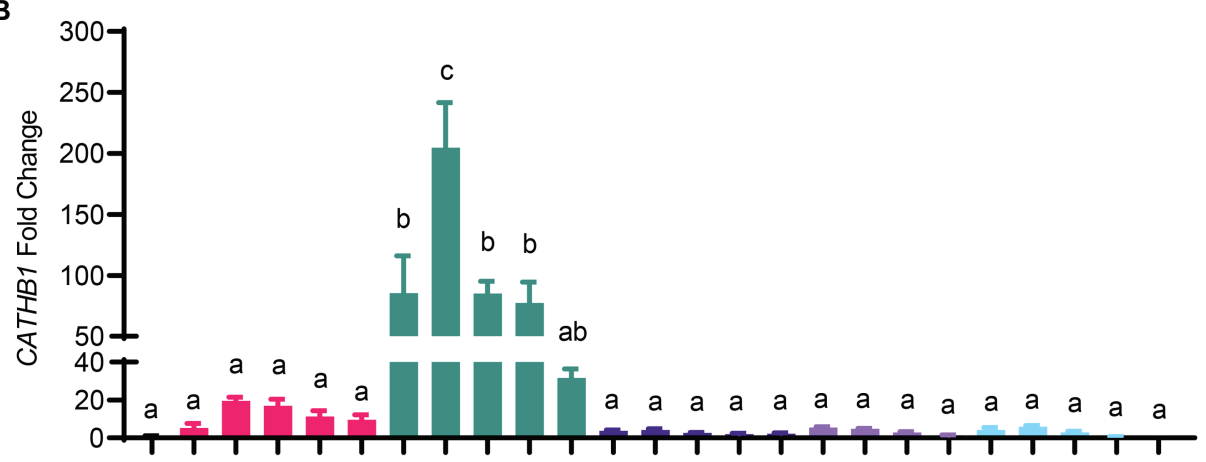

C

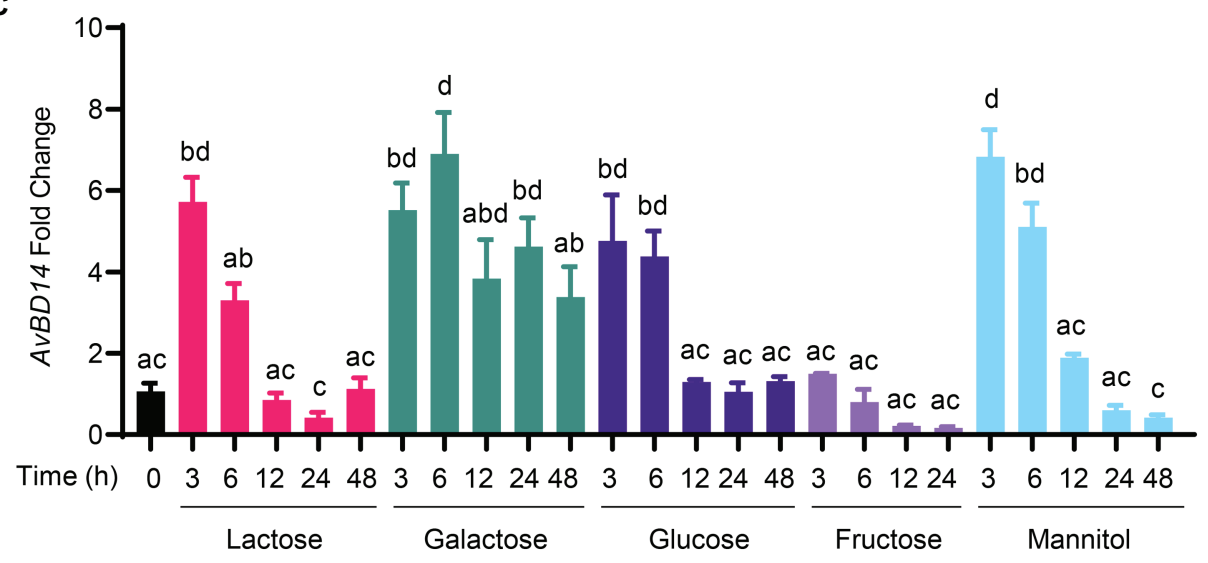

FIGURE 2 | Time-dependent induction of host defense peptide (HDP) expression by sugars. Chicken HD11 macrophages were stimulated in duplicate with $0.2 \mathrm{M}$ of indicated sugars for 3, 6, 12, 24, or 48h. Cells were then subjected to RNA isolation and RT-qPCR analysis of gene expressions of avian $\beta$-defensin 9 (AvBD9) (A), cathelicidin-B1 (CATHB1) (B), and AvBD14 (C). Results are expressed as means \pm SEM of 2-3 independent experiments. The bars without common superscript letters denote statistical significance $(p<0.05)$ as determined by one-way ANOVA and post hoc Tukey's test.

HD11 cells at $6 \mathrm{~h}$ (Figure 5B). A clear synergy was also observed between butyrate and lactose in MUC2 induction particularly at 12 and $24 \mathrm{~h}$ (Figure 5B). On the other hand, CLDN1 was prominently induced by butyrate, but not by lactose, and no obvious synergy was observed (Figure 5C).

To evaluate whether other mono- and disaccharides could also synergize with butyrate in improving HDP expression, HD11 cells were treated with butyrate and different sugars individually or in combination for $12 \mathrm{~h}$. Similarly, galactose, glucose, and trehalose showed a dramatic synergy in $A v B D 9$ induction (Figure 6A). Moreover, galactose and trehalose synergized with butyrate more strongly than lactose in CATHB1 induction, whereas glucose and mannitol failed to induce CATHB1 expression showing no synergy with butyrate (Figure 6B). In the case of $A v B D 14$, none of the sugars investigated exhibited synergy with butyrate (Figure 6C).

To confirm whether the HDP-inducing synergy between butyrate and sugars also occurs in other cell types, chicken jejunal explants were prepared and treated with butyrate and lactose separately or together. Butyrate $(2 \mathrm{mM})$ and lactose $(0.1 \mathrm{M})$ gave an approximately 120 - and 20-fold induction of $A v B D 9$, respectively, but more importantly, a marked synergy was observed, 


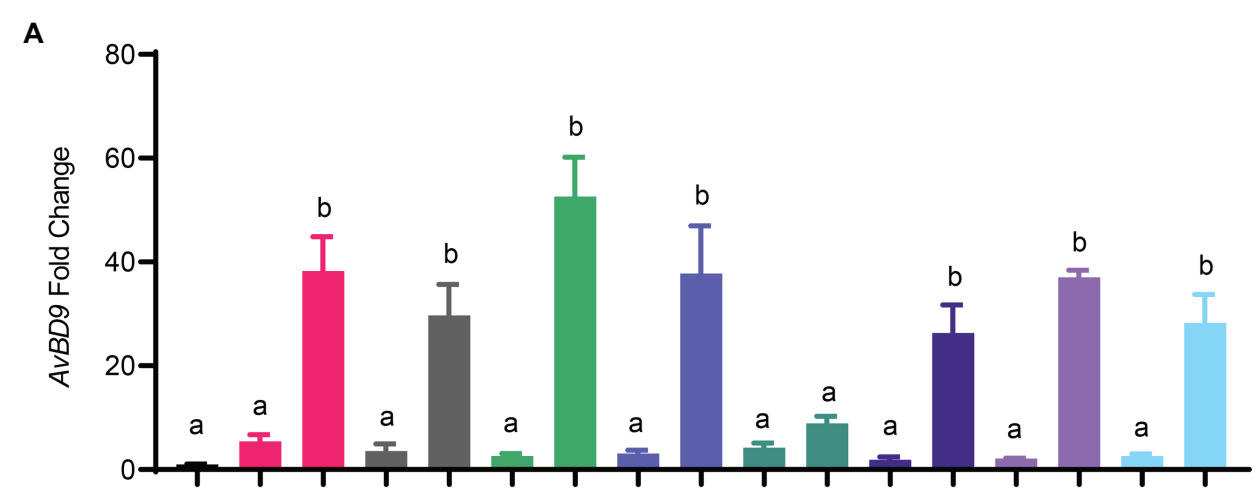

B

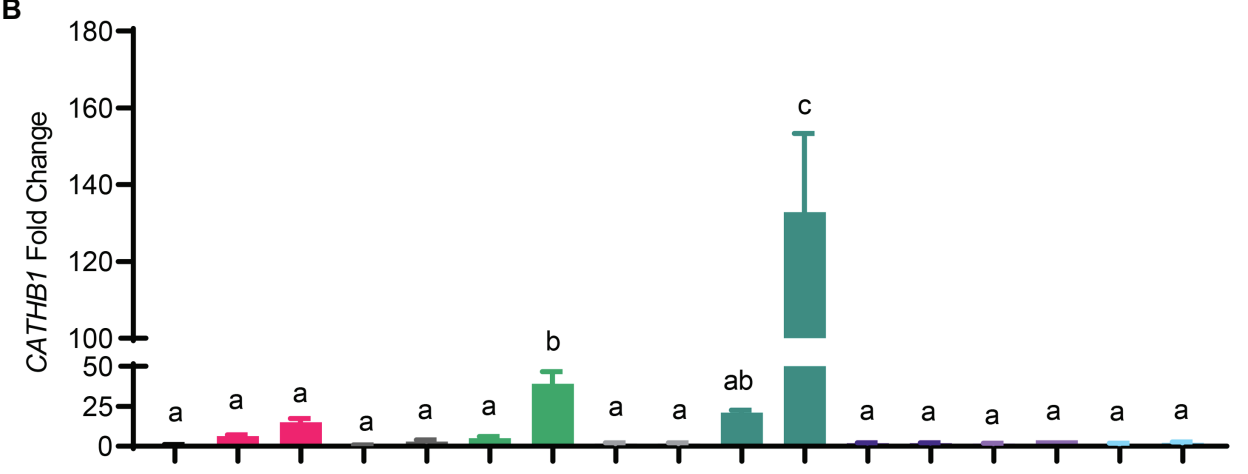

C

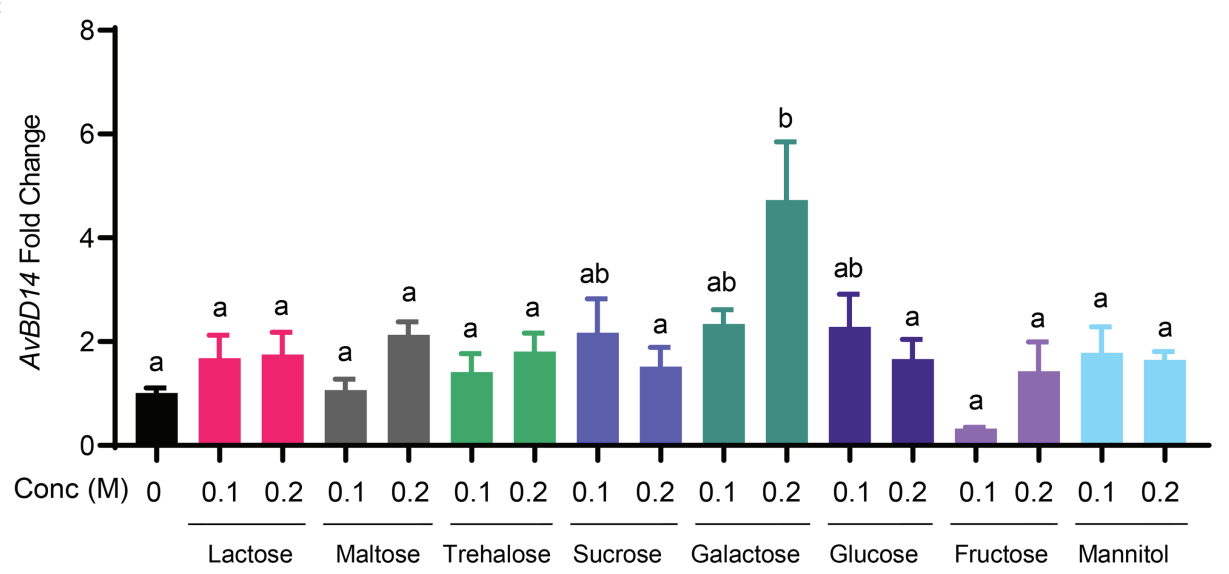

FIGURE 3 | Dose-dependent induction of chicken HDP expression by sugars. Chicken HD11 macrophage cells were stimulated in duplicate with 0.1 or $0.2 \mathrm{M}$ of indicated sugars for $6 \mathrm{~h}$, followed by RNA isolation and RT-qPCR analysis of the gene expressions of AvBD9 (A), CATHB1 (B), and AvBD14 (C). Results are expressed as means \pm SEM of $2-3$ independent experiments. The bars without common superscript letters denote statistical significance $(p<0.05)$ as determined by one-way ANOVA and post hoc Tukey's test.

showing an approximately 550-fold increase in response to both compounds (Figure 7). To further examine how inflammatory response is affected by butyrate and lactose, HD11 cells were treated with butyrate or lactose individually or in combination in the presence or absence of bacterial lipopolysaccharide (LPS). As expected, butyrate was anti-inflammatory without altering interleukin-1 $\beta$ (IL-1 $\beta)$ expression; however, lactose caused a minimum induction of $I L-1 \beta$ expression (Figure 8). Importantly, lactose, butyrate, and the combination significantly reduced LPS-induced IL-1 $\beta$ expression, although no synergistic suppression was observed (Figure 8), suggesting an overall anti-inflammatory effect of the butyrate/lactose combination.

\section{Role of Histone Acetylation and MAPK, NF- $\kappa B$, and cAMP Signaling in HDP Gene Expression Induced by Butyrate and Lactose}

Butyrate induces HDP expression in chickens and humans mainly by acting as a HDACi (Kida et al., 2006; Robinson 


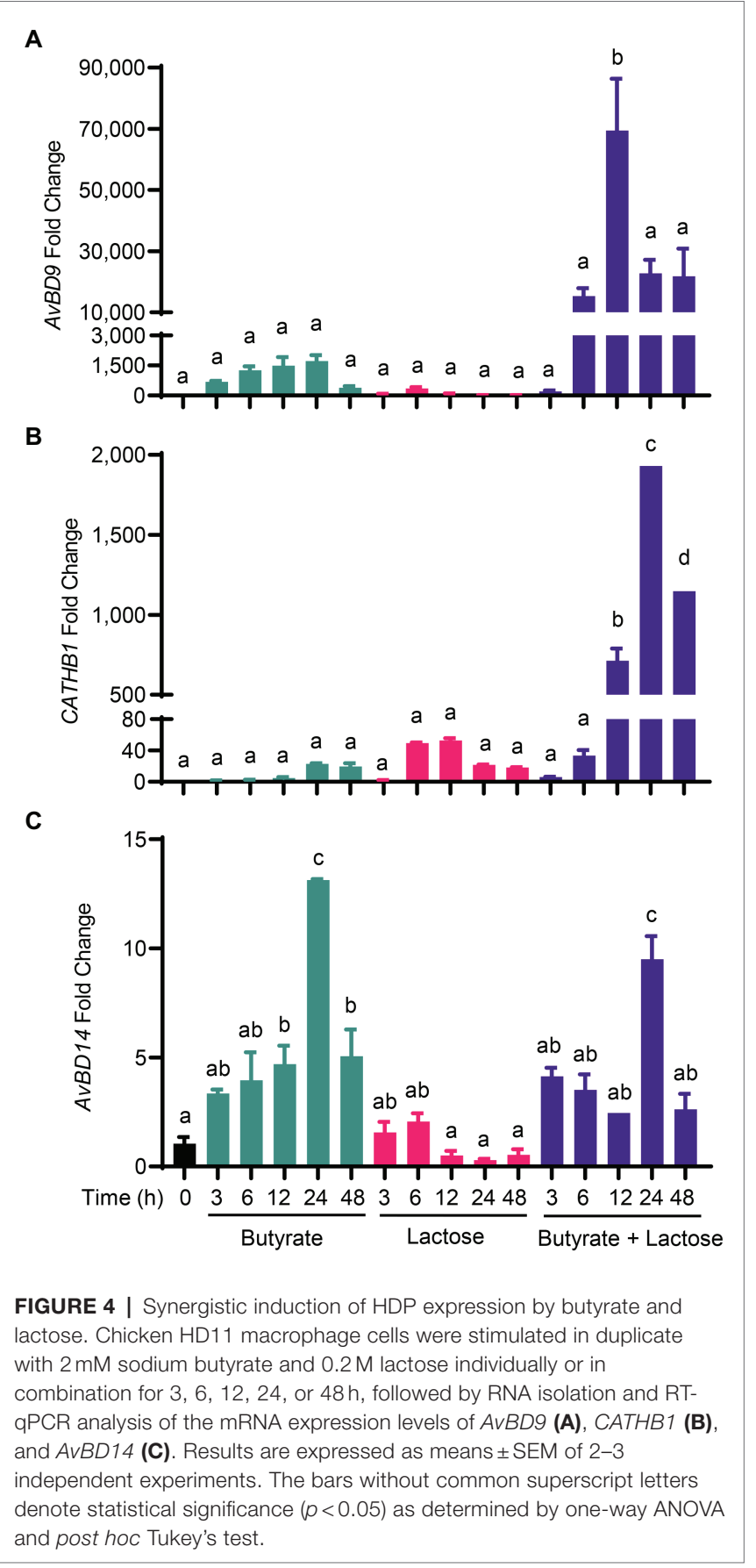

et al., 2018). To examine the impact of butyrate and lactose on histone acetylation, chicken HD11 cells were treated with butyrate and lactose individually or in combination for 6 , 12 , and $24 \mathrm{~h}$, followed by evaluation of the acetylation status of histone 4 (H4) using immunoblotting. As expected, butyrate triggered obvious $\mathrm{H} 4$ acetylation at $12 \mathrm{~h}$ and the acetylation become more pronounced at $24 \mathrm{~h}$, while lactose had no impact on histone acetylation at any time point (Figure 9). A combination of both butyrate and lactose apparently accelerated and intensified histone acetylation, with $\mathrm{H} 4$ acetylation occurring evidently as early as $6 \mathrm{~h}$, peaking at $12 \mathrm{~h}$, and sustained at $24 \mathrm{~h}$.

To examine the role of MAPK, NF- $\mathrm{BB}$, and cAMP signaling pathways in butyrate- and lactose-mediated synergy in $A v B D 9$ induction, chicken HD11 cells were treated with butyrate and/ or lactose for $24 \mathrm{~h}$ in the presence or absence of specific inhibitors for each pathway. As expected, all inhibitors alone had a minimum influence on $A v B D 9$ gene expression, and inhibition of p38 MAPK (with SB203580), NF-KB (with QNZ), and cAMP pathways (with SQ22536) also had no influence on lactose-induced $A v B D 9$ expression (Figure 10A). On the other hand, inhibition of p38 MAPK, JNK (with SP600125), NF- $\kappa B$, and cAMP pathways partially blocked butyrate-induced $A v B D 9$ expression, and the same four signaling pathways were similarly involved in $A v B D 9$ induction by a combination of butyrate and lactose (Figure 10A). Surprisingly, blocking the MAPK kinase 1/2 (MEK1/2) pathway by PD98059 significantly potentiated $A v B D 9$ gene expression induced by lactose, butyrate, or the combination (Figure 10A).

To further probe the involvement of the Ras-Raf-MEK1/2ERK1/2-RSK pathway, inhibitors specific for kinases at different steps (Figure 10B) were employed. Consistently, inhibition of MEK1/2 with low concentrations of PD98059 and U0126 enhanced $A v B D 9$ gene expression, while increasing the concentrations of PD98059 and U0126 significantly suppressed $A v B D 9$ expression (Figure 10C). Inhibition of Raf with BAY43 also dose-dependently reduced $A v B D 9$ expression. The AvBD9suppressing effect of blocking ERK1/2 and ribosomal S6 kinase (RSK) with AG126 and SL0101 was much more pronounced (Figure 10C). Collectively, these results suggested that, similar to the p38 MAPK and JNK pathways, the MEK-ERK pathway is also involved in butyrate-mediated HDP induction.

\section{DISCUSSION}

Sugars include mono- and disaccharides and constitute a group of dietary carbohydrates consisting of 1-2 simple sugar units, while oligosaccharides contain 3-9 sugar units, and polysaccharides contain $>9$ sugar units (Cummings and Stephen, 2007). All carbohydrates need to be broken down into monosaccharides to be utilized by animal hosts. Glucose and galactose are transported and taken up by the intestinal epithelial cells similarly through the involvement of sodium/glucose cotransporter 1 (SGLT1) and glucose transporter 2 (GLUT2), while GLUT2 and GLUT5 are involved in fructose transportation and absorption (Elferink et al., 2020). Disaccharides such as lactose, maltose, and trehalose lack the mechanism to be transported directed into intestinal epithelial cells and have to be broken down into two units of monosaccharides by different enzymes in the GI tract. Extended from an earlier study in humans (Cederlund et al., 2013), we have confirmed the conservation of the HDP-inducing activity of sugars in the chicken, a non-mammalian species, and further revealed a pronounced synergy between sugars and butyrate in augmenting chicken HDP expression. All eight most common sugars examined in this study including three monosaccharides, four 


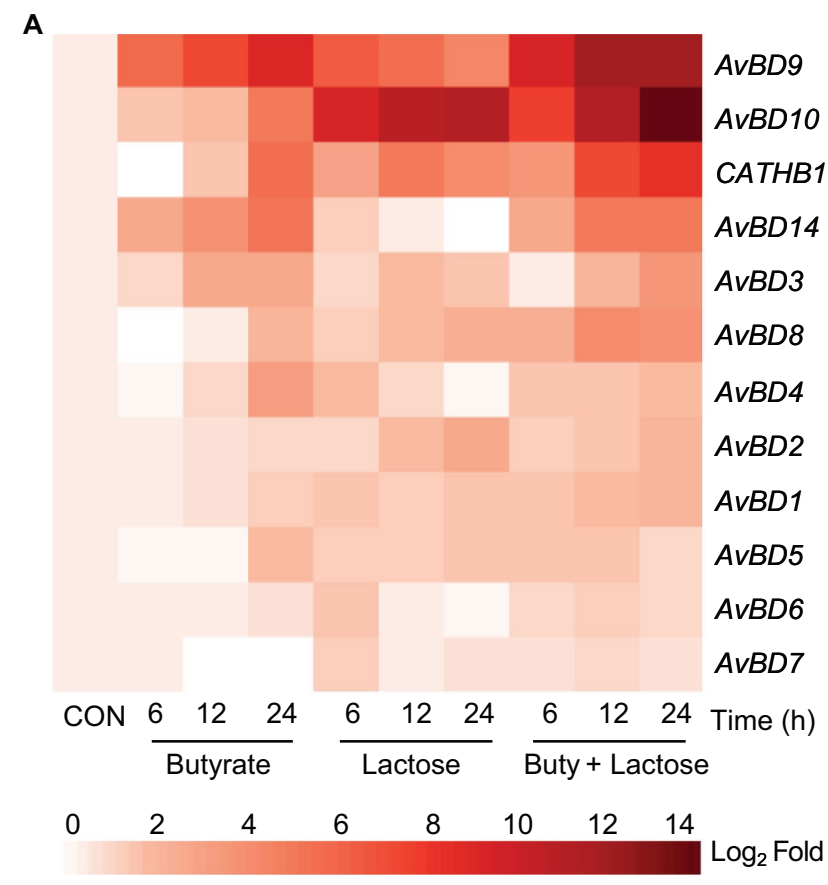

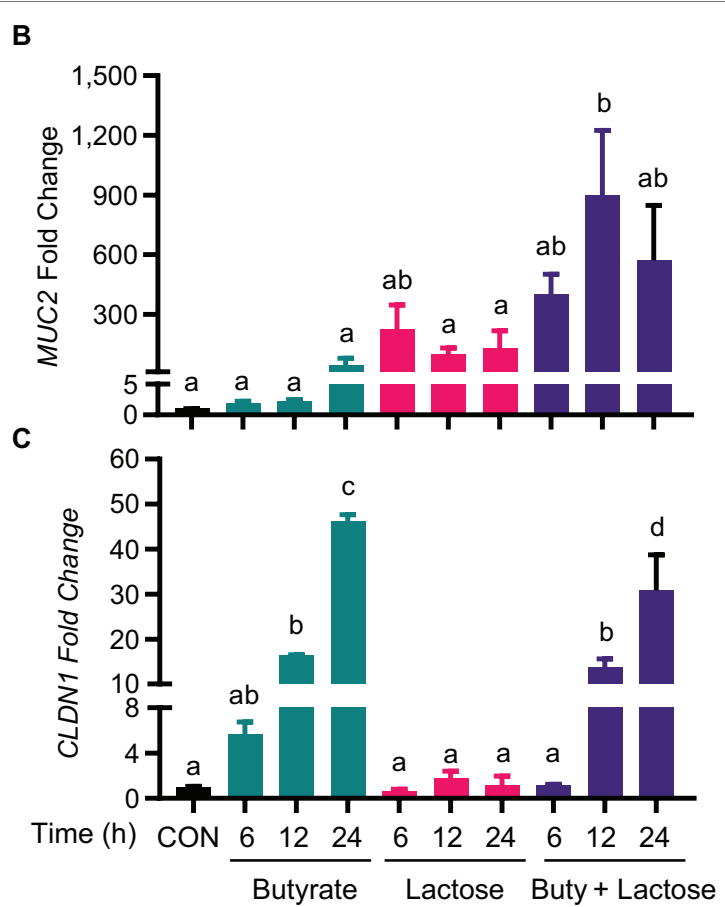

FIGURE 5 | Synergistic induction of HDP and barrier function gene expression by butyrate and lactose. Chicken HD11 cells were stimulated in duplicate with 2 mM sodium butyrate and $0.2 \mathrm{M}$ lactose individually or in combination for 6,12 , or $24 \mathrm{~h}$, followed by RNA isolation and RT-qPCR analysis of the mRNA expression levels of multiple HDP genes (A), mucin 2 (MUC2) (B), and claudin 1 (CLDN1) (C). Results are expressed as means \pm SEM of two independent experiments. The bars without common superscript letters denote statistical significance $(p<0.05)$ as determined by one-way ANOVA and post hoc Tukey's test.

disaccharides, and a sugar alcohol have the ability to induce the expression of certain HDP genes.

We have found that sugar-induced HDP expression is both gene- and sugar-specific. Among all chicken HDP genes, $A v B D 9$ and $A v B D 10$ are most readily inducible by lactose, while other genes are moderately or minimally induced. Among all sugars, $A v B D 9$ is uniformly induced, but other HDP genes exhibit a clear preference. For example, galactose is a potent inducer of CATHB1 gene expression, while trehalose and lactose have a modest activity, and many other sugars are minimally active in CATHB1 induction. On the other hand, $A v B D 14$ is minimally regulated by virtually all mono- and disaccharides tested. These results are consistent with an earlier study in humans, where trehalose is the most active in human CAMP gene induction in human HT-29 epithelial cells, with the potency gradually decreased in the order of maltose, lactose, glucose, and galactose (Cederlund et al., 2013). Gene-specific induction of HDPs was also observed with other small-molecule compounds such as butyrate (Sunkara et al., 2011, 2012; Zeng et al., 2013) and vitamin $\mathrm{D}_{3}$ (Zhang et al., 2016). For example, approximately a half number of chicken HDP genes are induced by butyrate, with $A v B D 9$ being the most inducible in chicken HD11 cells (Sunkara et al., 2012).

The synergy between butyrate and sugars also shows similar gene- and sugar-specific patterns of HDP regulation. All sugars synergize with butyrate in $A v B D 9$ induction with a similar potency; however, only galactose, trehalose, and lactose show a synergistic effect with butyrate in CATHB1 induction, with galactose and trehalose giving much stronger synergy than lactose. It is noted that the kinetics of HDP induction by sugars or the sugar/butyrate combination is much different from most other HDP-inducing compounds. While it takes $24-48 \mathrm{~h}$ for butyrate, fatty acids, $\mathrm{HDACi}$, and vitamin $\mathrm{D}_{3}$ to achieve maximum $\mathrm{HDP}$ induction (Wang et al., 2004; Sunkara et al., 2011, 2012; Jiang et al., 2013; Zeng et al., 2013; Deng et al., 2018; Lyu et al., 2018), peak HDP expression occurs as early as 3-6h with a sugar.

All sugars tested in this study are capable of inducing $A v B D 9$ gene expression; however, the underlying mechanism remains largely unknown. An earlier human study revealed a partial involvement of the JNK and p38 MAPK pathways in lactoseinduced human CAMP gene expression in HT-29 cells (Cederlund et al., 2013). However, neither MAPK pathway plays a critical role in lactose-mediated $A v B D 9$ induction. Such a discrepancy might be due to a difference in species, cell type, or HDP gene examined in the two studies. However, we have confirmed that all three canonical MAPK signaling pathways (JNK, p38 MAPK, and ERK1/2) are involved in the synergy in $A v B D 9$ gene induction by the lactose/butyrate combination. Although they are dispensable for lactose-induced $A v B D 9$ expression, $\mathrm{NF}-\kappa \mathrm{B}$ and $\mathrm{cAMP}$ signaling are partially responsible for the lactose/butyrate synergy, which is perhaps unsurprising, given the fact that sugars such as glucose are known to activate cAMP (Tengholm and Gylfe, 2017) and NF-кB (Kracht et al., 2020).

Butyrate is well known to induce HDP expression mainly by acting as an HDACi (Xiong et al., 2016; Rodriguez-Carlos et al., 2021). In this study, we have further revealed that although 


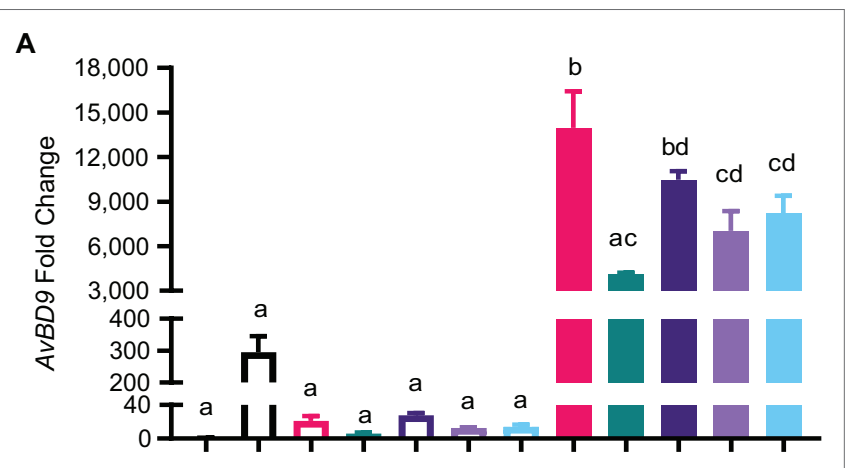

B

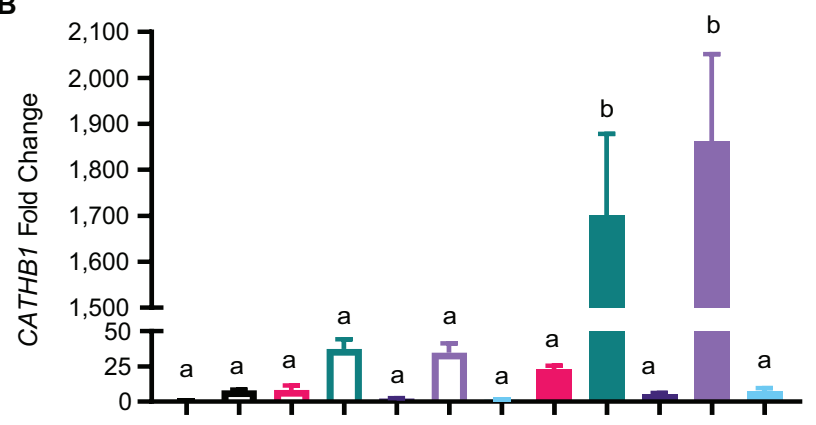

C

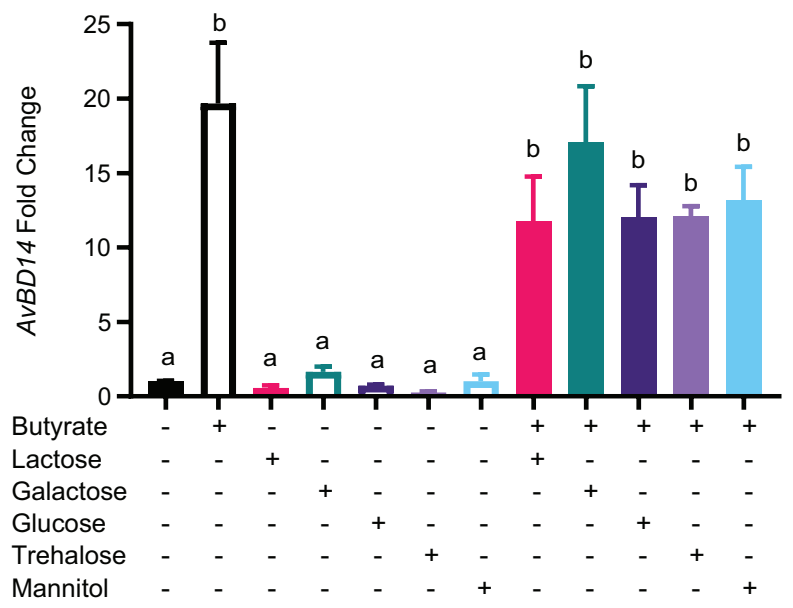

FIGURE 6 | Synergistic induction of HDP expression by butyrate and sugars. Chicken HD11 cells were stimulated in duplicate with $2 \mathrm{mM}$ butyrate and $0.2 \mathrm{M}$ of indicated sugars separately or in combination for $12 \mathrm{~h}$, followed by RNA isolation and RT-qPCR analysis of the mRNA expression levels of AvBD9 (A), CATHB1 (B), and AvBD14 (C). Results are expressed as means \pm SEM of 2-3 independent experiments. The bars without common superscript letters denote statistical significance $(p<0.05)$ as determined by one-way ANOVA and post hoc Tukey's test.

lactose has no direct impact on histone acetylation, histones are hyper-acetylated in response to a combination of lactose and butyrate. The exact mechanism is unknown, but it is tempting to speculate that lactose may act similarly as glucose, which has been extensively studied and shown to regulate gene expression through p300, also known as EP300 (Chen et al., 2010), a central transcriptional coactivator with histone acetyltransferase activity to enhance histone acetylation, chromatin relaxation, and gene transcription (Dancy and Cole, 2015). Glucose-mediated enhancement of p300 phosphorylation was recently shown to mediate through activation of $5^{\prime}$ adenosine monophosphateactivated protein kinase (AMPK) in a metabolic context-dependent manner (Gutierrez-Salmeron et al., 2020). AMPK is normally activated during glucose deprivation, but can also be activated in response to high glucose if glucose is blocked for glycogen synthesis inside a cell (Gutierrez-Salmeron et al., 2020).

It is worth noting that $25-50 \mathrm{mM}$ glucose was mostly used in the literature to activate AMPK or induce phosphorylation of p300. Much higher concentrations $(0.1-0.2 \mathrm{M})$ of glucose and other sugars have to be used in order to achieve optimal HDP induction in this study. The reason is unclear, but unlikely due to osmotic stress, because of the facts that: (1) up to $0.4 \mathrm{M}$ $\mathrm{NaCl}$ or $\mathrm{KCl}$ fails to induce human CAMP gene in HT-29 cells, whereas different sugars do so readily (Cederlund et al., 2013); (2) certain HDP genes such as AvBD14 are barely induced by any sugar even at $0.2 \mathrm{M}$ (Figure 3); and (3) HDP genes such as $C A T H B 1$ are only induced by few, but not all, sugars (Figures 2, 3). Mannitol, a non-metabolizable and membraneimpermeable sugar alcohol (Chen et al., 2020) induces chicken $A v B D 9$ gene and also synergizes with butyrate in $A v B D 9$ induction, similar to most other sugars, which is consistent with its ability to induce human CAMP gene (Cederlund et al., 2013). Additionally, chickens produce maltase and sucrase to break down sucrose and maltose, respectively, but appear to lack lactase to break down and take up lactose (Siddons, 1969; Siddons and Coates, 1972). Lactose is nevertheless still capable of inducing most HDP genes in chicken cells. These observations collectively suggest a presence of transmembrane receptors to mediate sugarinduced HDP expression. In fact, sugars and sweeteners can bind to ubiquitously expressed sweet taste receptors T1R2 and T1R3 to activate multiple complex signaling pathways in mammals (Lee and Owyang, 2017; Von Molitor et al., 2021) and also in avian species (Niknafs and Roura, 2018; Roura and Foster, 2018). It will be important to examine the involvement of taste receptors or other receptors in sugar-mediated HDP induction.

In addition to upregulating HDP expression, lactose and likely other sugars also strongly augment the gene expression of MUC2, which is in turn translated to the predominant mucin protein in the intestinal epithelium (Vancamelbeke and Vermeire, 2017; Liu et al., 2020). Butyrate is also well-known to induce MUC2 (Bach Knudsen et al., 2018). The synergy between butyrate and lactose in inducing MUC2 may potentiate their protection of the epithelial barrier. With an additional ability to suppress LPS-induced inflammatory response (Figure 8), butyrate and lactose have the potential to enhance gut health and alleviate infections. In fact, butyrate and $2.5 \%$ lactose have been separately used in chickens with a beneficial effect on alleviating infections such as necrotic enteritis (Mcreynolds et al., 2007; Liu et al., 2019). Although the mechanism of action was not studied earlier, augmenting HDP gene expression and barrier function while suppressing inflammation may be at least partially responsible for enhanced disease resistance in chickens fed butyrate or lactose. Although a combination of butyrate and lactose is yet to be tested, we recently found chickens supplemented with a mixture of $0.1 \%$ encapsulated sodium butyrate, $1 \%$ lactose, and $5-10 \mathrm{ppm}$ forskolin-containing plant extract to 


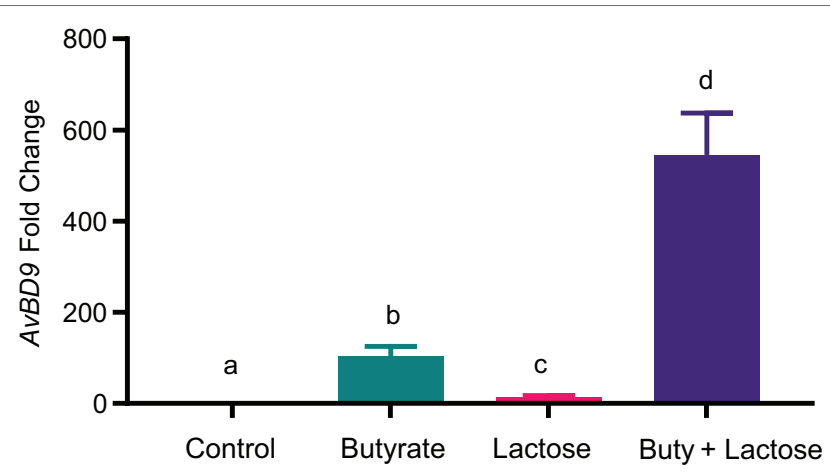

FIGURE 7 | Synergistic induction of AvBD9 gene expression in chicken jejunal explants by butyrate and lactose. Chicken jejunal explants were treated in duplicate with $2 \mathrm{mM}$ sodium butyrate and $0.1 \mathrm{M}$ lactose individually or in combination for $24 \mathrm{~h}$, followed by RNA isolation and RT-qPCR analysis of AvBD9 expression. Results are shown as means \pm SEM of three independent experiments. The bars without common superscript letters denote statistical significance $(p<0.05)$ as determined by one-way ANOVA and post hoc Tukey's test.

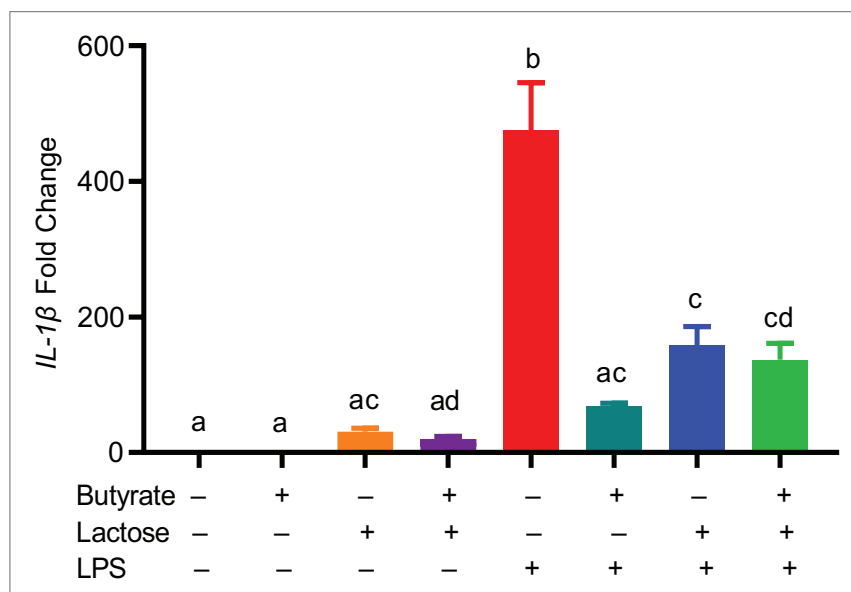

FIGURE 8 | Suppression of lipopolysaccharide (LPS)-induced interleukin $1 \beta$ $(I L-1 \beta)$ by butyrate and lactose. Chicken HD11 cells were treated in duplicate with $2 \mathrm{mM}$ butyrate, $0.1 \mathrm{M}$ lactose, or in combination for $1 \mathrm{~h}$, followed by stimulation with $10 \mathrm{ng} / \mathrm{ml}$ LPS for another $3 \mathrm{~h}$ and RT-qPCR measurement of $I L-1 \beta$ gene expression. The results presented means \pm SEM of two independent experiments. The bars without common superscript letters denote statistical significance $(p<0.05)$ as determined by one-way ANOVA and post hoc Tukey's test.

be protected from both necrotic enteritis and coccidiosis (Yang et al., 2021). Butyrate/forskolin-mediated protection of chickens from necrotic enteritis is also mediated through enhancing HDP expression and barrier function (Robinson et al., 2021).

This study is focused on mono- and disaccharides. The role of dietary oligosaccharides and polysaccharides in regulating HDP gene expression is largely unknown, except that two human milk oligosaccharides were recently found to increase human $\beta$-defensin 2 protein synthesis, but not other HDPs or inflammatory cytokines (Gursoy et al., 2021). It will be interesting to explore possible HDP-inducing and other immunomodulatory roles of commonly

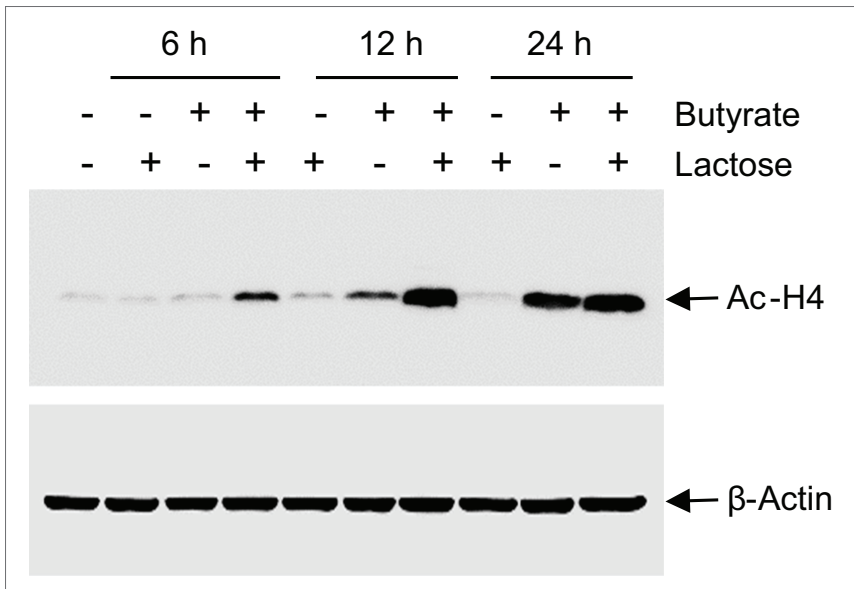

FIGURE 9 | Acetylation of histone $\mathrm{H} 4$ in response to butyrate and lactose. Chicken HD11 cells were treated with $0.2 \mathrm{M}$ lactose with or without $2 \mathrm{mM}$ sodium butyrate for 6,12 , or $24 \mathrm{~h}$, followed by Western blot analysis for acetylation of histone $\mathrm{H} 4$. $\beta$-actin was also probed to show an equal amount of protein loading in each lane. The results are a representative of two independent experiments.

used dietary oligosaccharides and polysaccharides such as fructooligosaccharides, galacto-oligosaccharides, xylo-oligosaccharides, mannan-oligosaccharides, and inulin, all of which are being actively explored as prebiotics to manage the gut microbiome, gut health, and diseases (Zhu et al., 2019).

\section{CONCLUSION}

Mono- and disaccharide sugars are capable of inducing the expressions of HDP genes in chicken HD11 macrophages and jejunal explants in gene- and sugar-specific manners. Moreover, these sugars synergize with butyrate to further enhance chicken HDP expression. Additionally, lactose is synergistic with butyrate in upregulating MUC2 expression. Promoting histone hyper-acetylation is at least partially responsible for lactose- and butyrate-mediated synergy in $A v B D 9$ induction. MAPK, NF- $\mathrm{B}$, and cAMP signaling pathways are all involved in $A v B D 9$ expression induced by lactose and butyrate. Our results suggest a prospect for the development of a combination of sugars and butyrate as an antibiotic-alternative approach to infectious disease control and prevention.

\section{DATA AVAILABILITY STATEMENT}

The original contributions presented in the study are included in the article/supplementary material, further inquiries can be directed to the corresponding author.

\section{AUTHOR CONTRIBUTIONS}

QY, L-AF, WL, LTS, and KX conducted the experiments. QY, L-AF, and GZ performed data analysis. QY and L-AF drafted the 
A

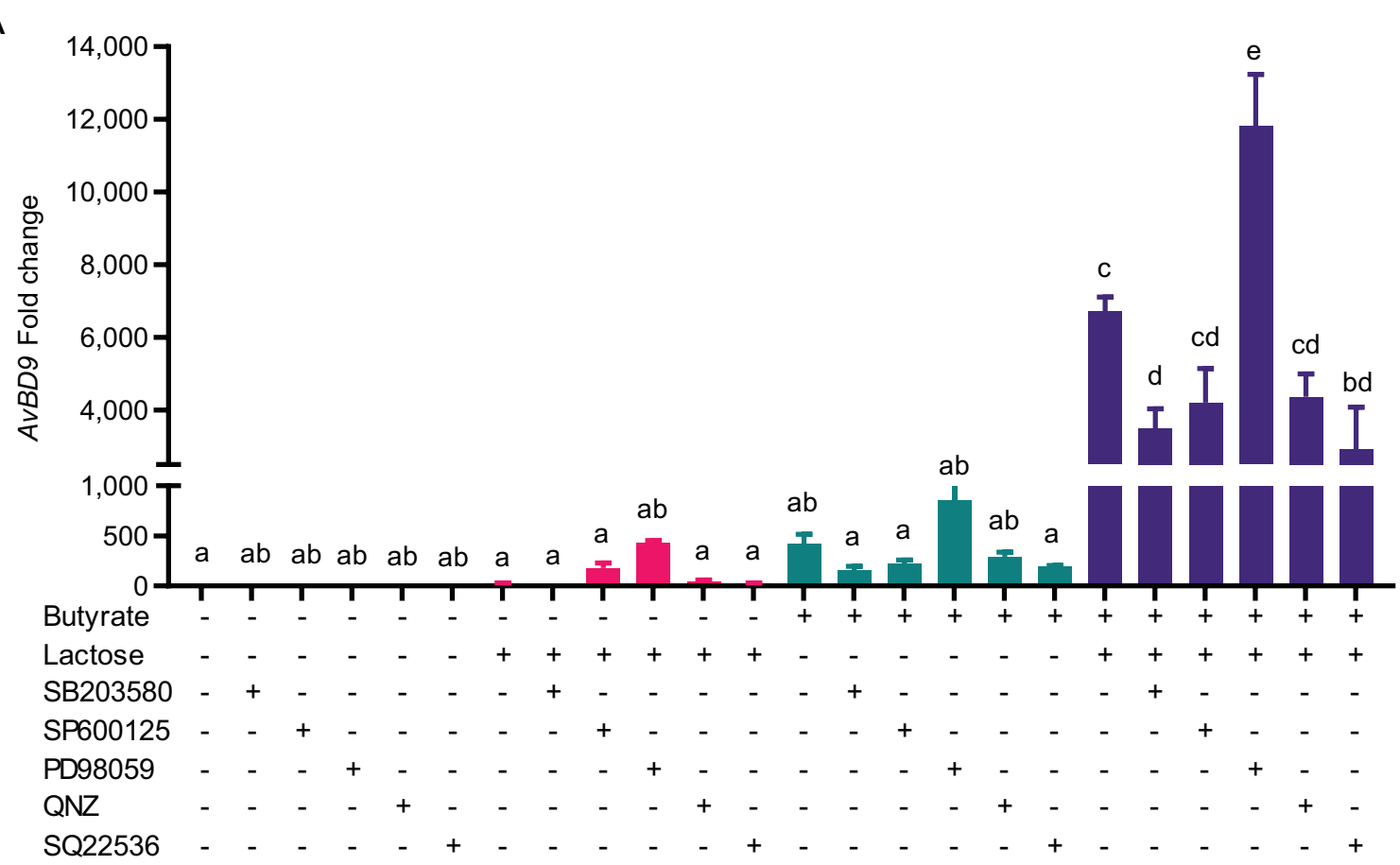

B

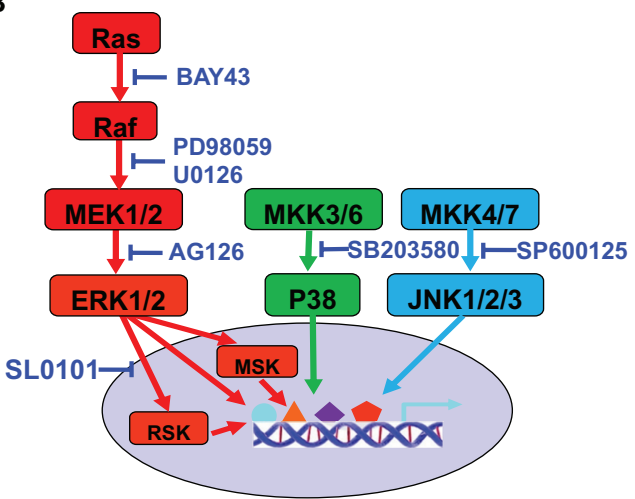

C

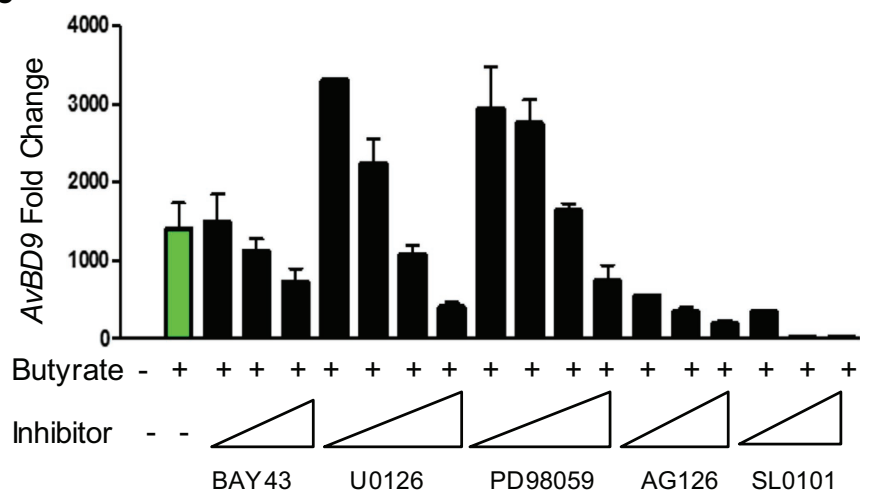

FIGURE 10 | Involvement of mitogen-activated protein kinase (MAPK), NF-кB, and cAMP signaling pathways in AvBD9 induction mediated by butyrate and lactose. (A) Chicken HD11 cells were pretreated for $1 \mathrm{~h}$ with or without a specific inhibitor for p38 MAPK (SB203580), JNK (SP600125), MEK1/2 (PD98059), NF-кB (QNZ), or cAMP signaling (SQ22536), followed by stimulation with $2 \mathrm{mM}$ sodium butyrate and $0.2 \mathrm{M}$ lactose separately or in combination for another $24 \mathrm{~h}$. (B) A schematic drawing of three canonical MAPK pathways showing the steps where specific inhibitors act. (C) HD11 cells were pretreated for $1 \mathrm{~h}$ with or without an indicated inhibitor for the Ras-Raf-MEK-ERK-RSK pathway, followed by stimulation with $2 \mathrm{mM}$ sodium butyrate for another $24 \mathrm{~h}$. RT-qPCR analysis of AvBD 9 expression was performed. Results are shown as means \pm SEM of 2-3 independent experiments. The bars without common superscript letters denote statistical significance $(p<0.05)$ as determined by one-way ANOVA and post hoc Tukey's test.

manuscript. GZ conceived the study and revised the manuscript. All authors contributed to the article and approved the submitted version.

\section{FUNDING}

This research was funded by the USDA National Institute of Food and Agriculture (grant nos. 2018-68003-27462 and 202067016-31619), Oklahoma Center for the Advancement of Science and Technology (grant no. AR19-027), the Ralph F. and Leila W. Boulware Endowment Fund, and Oklahoma Agricultural Experiment Station Project H-3112.

\section{ACKNOWLEDGMENTS}

The authors appreciate Hyun Lillehoj at the USDA-Agricultural Research Services for kindly providing HD11, a chicken macrophage cell line. 


\section{REFERENCES}

Bach Knudsen, K. E., Laerke, H. N., Hedemann, M. S., Nielsen, T. S., Ingerslev, A. K., Gundelund Nielsen, D. S., et al. (2018). Impact of dietmodulated butyrate production on intestinal barrier function and inflammation. Nutrients 10:1499. doi: 10.3390/nu10101499

Bergman, P., Raqib, R., Rekha, R. S., Agerberth, B., and Gudmundsson, G. H. (2020). Host directed therapy against infection by boosting innate immunity. Front. Immunol. 11:1209. doi: 10.3389/fimmu.2020.01209

Cederlund, A., Kai-Larsen, Y., Printz, G., Yoshio, H., Alvelius, G., Lagercrantz, H., et al. (2013). Lactose in human breast milk an inducer of innate immunity with implications for a role in intestinal homeostasis. PLoS One 8:e53876. doi: 10.1371/journal.pone.0053876

Chen, S., Feng, B., George, B., Chakrabarti, R., Chen, M., and Chakrabarti, S. (2010). Transcriptional coactivator p300 regulates glucose-induced gene expression in endothelial cells. Am. J. Physiol. Endocrinol. Metab. 298, E127-E137. doi: 10.1152/ajpendo.00432.2009

Chen, M., Zhang, W., Wu, H., Guang, C., and Mu, W. (2020). Mannitol: physiological functionalities, determination methods, biotechnological production, and applications. Appl. Microbiol. Biotechnol. 104, 6941-6951. doi: 10.1007/s00253-020-10757-y

Cruz Diaz, L. A., Flores Miramontes, M. G., Chavez Hurtado, P., Allen, K., Gonzalez Avila, M., and Prado Montes De Oca, E. (2015). Ascorbic acid, ultraviolet $\mathrm{C}$ rays, and glucose but not hyperthermia are elicitors of human beta-defensin 1 mRNA in normal keratinocytes. Biomed. Res. Int. 2015:714580. doi: $10.1155 / 2015 / 714580$

Cummings, J. H., and Stephen, A. M. (2007). Carbohydrate terminology and classification. Eur. J. Clin. Nutr. 61(Suppl. 1), S5-S18. doi: 10.1038/sj.ejcn.1602936

Dancy, B. M., and Cole, P. A. (2015). Protein lysine acetylation by p300/CBP. Chem. Rev. 115, 2419-2452. doi: 10.1021/cr500452k

Deng, Z., Wang, J., Lyu, W., Wieneke, X., Matts, R., Ma, X., et al. (2018). Development of a cell-based high-throughput screening assay to identify porcine host defense peptide-inducing compounds. J Immunol Res 2018:5492941. doi: 10.1155/2018/5492941

Elferink, H., Bruekers, J. P. J., Veeneman, G. H., and Boltje, T. J. (2020). A comprehensive overview of substrate specificity of glycoside hydrolases and transporters in the small intestine: "a gut feeling". Cell. Mol. Life Sci. 77, 4799-4826. doi: 10.1007/s00018-020-03564-1

Gombart, A. F., Borregaard, N., and Koeffler, H. P. (2005). Human cathelicidin antimicrobial peptide (CAMP) gene is a direct target of the vitamin D receptor and is strongly up-regulated in myeloid cells by 1,25-dihydroxyvitamin D3. FASEB J. 19, 1067-1077. doi: 10.1096/fi.04-3284com

Gursoy, U. K., Salli, K., Soderling, E., Gursoy, M., Hirvonen, J., and Ouwehand, A. C. (2021). Regulation of hBD-2, hBD-3, hCAP18/LL37, and proinflammatory cytokine secretion by human milk oligosaccharides in an organotypic oral mucosal model. Pathogens 10:739. doi: 10.3390/pathogens10060739

Gutierrez-Salmeron, M., Garcia-Martinez, J. M., Martinez-Useros, J., Fernandez-Acenero, M. J., Viollet, B., Olivier, S., et al. (2020). Paradoxical activation of AMPK by glucose drives selective EP300 activity in colorectal cancer. PLoS Biol. 18:e3000732. doi: 10.1371/journal.pbio.3000732

Hancock, R. E., Haney, E. F., and Gill, E. E. (2016). The immunology of host defence peptides: beyond antimicrobial activity. Nat. Rev. Immunol. 16, 321-334. doi: 10.1038/nri.2016.29

Jiang, W., Sunkara, L. T., Zeng, X., Deng, Z., Myers, S. M., and Zhang, G. (2013). Differential regulation of human cathelicidin LL-37 by free fatty acids and their analogs. Peptides 50, 129-138. doi: 10.1016/j.peptides.2013.10.008

Kida, Y., Shimizu, T., and Kuwano, K. (2006). Sodium butyrate up-regulates cathelicidin gene expression via activator protein-1 and histone acetylation at the promoter region in a human lung epithelial cell line, EBC-1. Mol. Immunol. 43, 1972-1981. doi: 10.1016/j.molimm.2005.11.014

Kracht, M., Muller-Ladner, U., and Schmitz, M. L. (2020). Mutual regulation of metabolic processes and proinflammatory NF-kappaB signaling. J. Allergy Clin. Immunol. 146, 694-705. doi: 10.1016/j.jaci.2020.07.027

Lan, C. C., Wu, C. S., Huang, S. M., Kuo, H. Y., Wu, I. H., Liang, C. W., et al. (2012). High-glucose environment reduces human beta-defensin-2 expression in human keratinocytes: implications for poor diabetic wound healing. Br. J. Dermatol. 166, 1221-1229. doi: 10.1111/j.1365-2133.2012.10847.x
Lan, C. C., Wu, C. S., Huang, S. M., Kuo, H. Y., Wu, I. H., Wen, C. H., et al (2011). High-glucose environment inhibits p38MAPK signaling and reduces human beta-defensin-3 expression [corrected] in keratinocytes. Mol. Med. 17, 771-779. doi: 10.2119/molmed.2010.00091

Lee, A. A., and Owyang, C. (2017). Sugars, sweet taste receptors, and brain responses. Nutrients 9:653. doi: 10.3390/nu9070653

Liu, J. D., Lumpkins, B., Mathis, G., Williams, S. M., and Fowler, J. (2019). Evaluation of encapsulated sodium butyrate with varying releasing times on growth performance and necrotic enteritis mitigation in broilers. Poult Sci. 98, 3240-3245. doi: 10.3382/ps/pez049

Liu, H., Wang, J., He, T., Becker, S., Zhang, G., Li, D., et al. (2018). Butyrate: a double-edged sword for health? Adv. Nutr. 9, 21-29. doi: 10.1093/advances/ $\mathrm{nmx} 009$

Liu, Y., Yu, X., Zhao, J., Zhang, H., Zhai, Q., and Chen, W. (2020). The role of MUC2 mucin in intestinal homeostasis and the impact of dietary components on MUC2 expression. Int. J. Biol. Macromol. 164, 884-891. doi: 10.1016/j.ijbiomac.2020.07.191

Lyu, W., Curtis, A. R., Sunkara, L. T., and Zhang, G. (2015). Transcriptional regulation of antimicrobial host defense peptides. Curr. Protein Pept. Sci. 16, 672-679. doi: 10.2174/1389203716666150630133432

Lyu, W., Deng, Z., Sunkara, L. T., Becker, S., Robinson, K., Matts, R., et al. (2018). High throughput screening for natural host defense peptide-inducing compounds as novel alternatives to antibiotics. Front. Cell. Infect. Microbiol. 8:191. doi: 10.3389/fcimb.2018.00191

Malik, A. N., and Al-Kafaji, G. (2007). Glucose regulation of beta-defensin-1 mRNA in human renal cells. Biochem. Biophys. Res. Commun. 353, 318-323. doi: $10.1016 /$ j.bbrc.2006.12.037

Manyi-Loh, C., Mamphweli, S., Meyer, E., and Okoh, A. (2018). Antibiotic use in agriculture and its consequential resistance in environmental sources: potential public health implications. Molecules 23:795. doi: 10.3390/molecules23040795

Mcewen, S. A., and Collignon, P. J. (2018). Antimicrobial resistance: a one health perspective. Microbiol. Spectr. 6:ARBA-0009-2017. doi: 10.1128/ microbiolspec.ARBA-0009-2017

Mcreynolds, J. L., Byrd, J. A., Genovese, K. J., Poole, T. L., Duke, S. E., Farnell, M. B., et al. (2007). Dietary lactose and its effect on the disease condition of necrotic enteritis. Poult. Sci. 86, 1656-1661. doi: 10.1093/ ps/86.8.1656

Montoya-Rosales, A., Castro-Garcia, P., Torres-Juarez, F., Enciso-Moreno, J. A., and Rivas-Santiago, B. (2016). Glucose levels affect LL-37 expression in monocyte-derived macrophages altering the Mycobacterium tuberculosis intracellular growth control. Microb. Pathog. 97, 148-153. doi: 10.1016/j. micpath.2016.06.002

Niknafs, S., and Roura, E. (2018). Nutrient sensing, taste and feed intake in avian species. Nutr. Res. Rev. 31, 256-266. doi: 10.1017/S0954422418000100

Robinson, K., Deng, Z., Hou, Y., and Zhang, G. (2015). Regulation of the intestinal barrier function by host defense peptides. Front. Vet. Sci. 2:57. doi: 10.3389/fvets.2015.00057

Robinson, K., Ma, X., Liu, Y., Qiao, S., Hou, Y., and Zhang, G. (2018). Dietary modulation of endogenous host defense peptide synthesis as an alternative approach to in-feed antibiotics. Anim. Nutr. 4, 160-169. doi: 10.1016/j. aninu.2018.01.003

Robinson, K., Yang, Q., Li, H., Zhang, L., Aylward, B., Arsenault, R. J., et al. (2021). Butyrate and forskolin augment host defense, barrier function, and disease resistance without eliciting inflammation. Front. Nutr. 8:778424. doi: 10.3389/fnut.2021.778424

Rodriguez-Carlos, A., Jacobo-Delgado, Y. M., Santos-Mena, A. O., and Rivas-Santiago, B. (2021). Modulation of cathelicidin and defensins by histone deacetylase inhibitors: a potential treatment for multi-drug resistant infectious diseases. Peptides 140:170527. doi: 10.1016/j.peptides.2021.170527

Roura, E., and Foster, S. R. (2018). Nutrient-sensing biology in mammals and birds. Annu. Rev. Anim. Biosci. 6, 197-225. doi: 10.1146/annurevanimal-030117-014740

Schauber, J., Svanholm, C., Termen, S., Iffland, K., Menzel, T., Scheppach, W., et al. (2003). Expression of the cathelicidin LL-37 is modulated by short chain fatty acids in colonocytes: relevance of signalling pathways. Gut 52, 735-741. doi: 10.1136/gut.52.5.735

Siddons, R. C. (1969). Intestinal disaccharidase activities in the chick. Biochem. J. 112, 51-59. doi: 10.1042/bj1120051 
Siddons, R. C., and Coates, M. E. (1972). The influence of the intestinal microflora on disaccharidase activities in the chick. Br. J. Nutr. 27 101-112. doi: $10.1079 /$ bjn19720074

Sunkara, L. T., Achanta, M., Schreiber, N. B., Bommineni, Y. R., Dai, G., Jiang, W., et al. (2011). Butyrate enhances disease resistance of chickens by inducing antimicrobial host defense peptide gene expression. PLoS One 6:e27225. doi: 10.1371/journal.pone.0027225

Sunkara, L. T., Jiang, W., and Zhang, G. (2012). Modulation of antimicrobial host defense peptide gene expression by free fatty acids. PLoS One 7:e49558. doi: 10.1371/journal.pone.0049558

Sunkara, L. T., Zeng, X., Curtis, A. R., and Zhang, G. (2014). Cyclic AMP synergizes with butyrate in promoting beta-defensin 9 expression in chickens. Mol. Immunol. 57, 171-180. doi: 10.1016/j.molimm.2013.09.003

Tengholm, A., and Gylfe, E. (2017). cAMP signalling in insulin and glucagon secretion. Diabetes Obes. Metab. 19(Suppl. 1), 42-53. doi: 10.1111/dom.12993

Ting, D. S. J., Beuerman, R. W., Dua, H. S., Lakshminarayanan, R., and Mohammed, I. (2020). Strategies in translating the therapeutic potentials of host defense peptides. Front. Immunol. 11:983. doi: 10.3389/fimmu.2020.00983

Vancamelbeke, M., and Vermeire, S. (2017). The intestinal barrier: a fundamental role in health and disease. Expert Rev. Gastroenterol. Hepatol. 11, 821-834. doi: 10.1080/17474124.2017.1343143

Von Molitor, E., Riedel, K., Krohn, M., Hafner, M., Rudolf, R., and Cesetti, T. (2021). Sweet taste is complex: signaling cascades and circuits involved in sweet sensation. Front. Hum. Neurosci. 15:667709. doi: 10.3389/ fnhum.2021.667709

Wang, T. T., Nestel, F. P., Bourdeau, V., Nagai, Y., Wang, Q., Liao, J., et al. (2004). Cutting edge: 1,25-dihydroxyvitamin D3 is a direct inducer of antimicrobial peptide gene expression. J. Immunol. 173, 2909-2912. doi: 10.4049/jimmunol.173.5.2909

Xiong, H., Guo, B., Gan, Z., Song, D., Lu, Z., Yi, H., et al. (2016). Butyrate upregulates endogenous host defense peptides to enhance disease resistance in piglets via histone deacetylase inhibition. Sci. Rep. 6:27070. doi: 10.1038/srep27070

Yang, Q., Whitmore, M. A., Robinson, K., Lyu, W., and Zhang, G. (2021). Butyrate, forskolin, and lactose synergistically enhance disease resistance by inducing the expression of the genes involved in innate host defense and barrier function. Antibiotics 10:1175. doi: 10.3390/antibiotics10101175

Zeng, X., Sunkara, L. T., Jiang, W., Bible, M., Carter, S., Ma, X., et al. (2013). Induction of porcine host defense peptide gene expression by short-chain fatty acids and their analogs. PLoS One 8:e72922. doi: 10.1371/journal. pone. 0083753

Zhang, L., Lu, L., Li, S., Zhang, G., Ouyang, L., Robinson, K., et al. (2016). 1,25-dihydroxyvitamin-D3 induces avian beta-defensin gene expression in chickens. PLoS One 11:e0154546. doi: 10.1371/journal.pone. 0168928

Zhang, G., and Sunkara, L. T. (2014). Avian antimicrobial host defense peptides: from biology to therapeutic applications. Pharmaceuticals 7, 220-247. doi 10.3390/ph7030220

Zhu, D., Yan, Q., Liu, J., Wu, X., and Jiang, Z. (2019). Can functional oligosaccharides reduce the risk of diabetes mellitus? FASEB J. 33, 11655-11667. doi: 10.1096/fj.201802802RRR

Conflict of Interest: The authors declare that the research was conducted in the absence of any commercial or financial relationships that could be construed as a potential conflict of interest.

Publisher's Note: All claims expressed in this article are solely those of the authors and do not necessarily represent those of their affiliated organizations, or those of the publisher, the editors and the reviewers. Any product that may be evaluated in this article, or claim that may be made by its manufacturer, is not guaranteed or endorsed by the publisher.

Copyright (c) 2021 Yang, Fong, Lyu, Sunkara, Xiao and Zhang. This is an openaccess article distributed under the terms of the Creative Commons Attribution License (CC BY). The use, distribution or reproduction in other forums is permitted, provided the original author(s) and the copyright owner(s) are credited and that the original publication in this journal is cited, in accordance with accepted academic practice. No use, distribution or reproduction is permitted which does not comply with these terms. 